\title{
Syntesis of Carbon Nanostructures Near Room Temperature Using Microwave PECVD
}

\author{
Flavio Henrique Oliveira Carvalho ${ }^{a}$, Alfredo Rodrigues Vaz,
} Stanislav Moshkalev ${ }^{b}$, Rogério Valentim Gelamo ${ }^{a *}$

\author{
${ }^{a}$ Universidade Federal do Triângulo Mineiro - UFTM, Av. Dr. Randolfo Borges Junior, 1250, \\ Bairro Univerdecidade, CEP 38064-200, Uberaba, MG, Brazil \\ ${ }^{b}$ Centro de Componentes Semicondutores, Universidade Estadual de Campinas - UNICAMP, \\ Rua João Pandia Calógeras, 90, Barão Geraldo, CEP 13083-870, Campinas, SP, Brazil
}

Received: June 24, 2015; Revised: August 10, 2015

\begin{abstract}
Carbon nanostructures (nanotubes, nanofibers and nanosponges) were synthesized onto $\mathrm{Si}(001)$ substrates using a microwave assisted plasma enhanced chemical vapor deposition (PECVD) from $\mathrm{C}_{2} \mathrm{H}_{2}-\mathrm{Ar}$ mixtures at low substrate temperatures $\left(120^{\circ} \mathrm{C}\right)$. Catalytic films $(\mathrm{Ni}$ and $\mathrm{Cu}) 3 \mathrm{~nm}$ thick were used. Different structures were formed, depending on the $\mathrm{C}_{2} \mathrm{H}_{2}$ partial pressure. Atomic force microscopy (AFM) and scanning electron spectroscopy (SEM) were employed for the morphological characterization of the catalytic films and the carbon nanostructures, respectively. Raman spectroscopy was used to identify carbon hybridization states. AFM was used to observe the morphology of the catalytic films. At low $\mathrm{C}_{2} \mathrm{H}_{2}$ partial pressures, nanotubes with nanospheres in their tips, growing from nanoholes were seen. With increasing $\mathrm{C}_{2} \mathrm{H}_{2}$ pressures, longer nanotubes were observed, reaching lengths from 300 to $500 \mathrm{~nm}$. In their growth, the nanotubes laterally touch each other, forming nanotube bundles, or nanofibers. For the higher $\mathrm{C}_{2} \mathrm{H}_{2}$ partial pressures, dense sponge-like (nanosponge) structures, consisting of a large number of bundles, are formed. From the Raman spectra, a mixture of sp2 and sp3 hybridizations were identified. Furthermore, the low substrate temperature at which depositions can be carried out, makes possible growth of carbon nanostructures on materials to which high temperatures would be deleterious.
\end{abstract}

Keywords: nanofiber, nanosponge, nanospheres, PECVD, microwave plasma, acetylene, AFM, SEM, Raman spectroscopy, carbon hybridization states

\section{Introduction}

Since the discovery of fullerenes ${ }^{1}$, and the first reports on the synthesis of carbon nanotubes ${ }^{2}$, investigations in carbon-based nanostructures have dramatically increased. As a consequence the use of carbon in new materials ${ }^{3}$ and composites $^{4}$ has grown steadily. Such structures found promising electrical $^{5}$, gas sensors ${ }^{6,7}$, supercapacitors $^{8}$ and nanomedicine ${ }^{9}$ applications.

Such carbon structures can be synthesized by the technique of plasma enhanced chemical vapor deposition (PECVD) and can be exemplified by diamond-like carbon ${ }^{10}$, carbon nanofibers ${ }^{11}$, carbon nanotubes ${ }^{12}$, amongst other forms of carbon $^{13}$. PECVD is indeed of great interest, as depositions can be carried out at relatively low substrate temperatures, thus avoiding the sometimes inconvenient temperature effects in materials in which the carbon structure is grown. Furthermore, due to the usually high deposition rate of PECVD ${ }^{14-18}$, the structures can be formed at short times, which is of interest in the industrial point of view.

In the PECVD technique, the carbon nanostructures strongly depend on the precursor gas (carbon-containing gas, usually a hydrocarbon, whose decomposition generates the carbon structures), diluent gas, such as $\mathrm{Ar}$ and $\mathrm{H}_{2}$, power applied to the discharge and substrate temperature. Chen and

*e-mail: rogelamo@gmail.com colleagues ${ }^{14}$ have used $\mathrm{CH}_{4}-\mathrm{H}_{2}$ mixtures to synthesize nanofibers. Choi et al. ${ }^{15}$. treated at $600^{\circ} \mathrm{C}$ a Ni catalyst layer deposited onto Ti-coated glass with hydrogen plasma at different microwave powers prior to carbon nanotubes synthesis using $\mathrm{CH}_{4}$ as a precursor gas. Wang \& Moore ${ }^{16}$ used radio frequency-PECVD with methane and mixtures of argon with hydrogen to obtain carbon nanotubes and carbon nanofibers at 140 to $180^{\circ} \mathrm{C}$ using Ni and FeNi catalyst films onto glass substrates. Hoffmann et al. ${ }^{17}$. obtained carbon nanotubes at relatively low temperature $\left(\sim 120^{\circ} \mathrm{C}\right)$ using a DC-PECVD system and mixtures of acetylene and ammonia onto prepatterned $\mathrm{Ni}$ catalyst particles in $\mathrm{SiO}_{2} / \mathrm{Si}$ substrate.

Regarding carbon nanofibres, they are formed from a catalytic process involving ultrafine particles (few $\mathrm{nm}$-diameter) of $\mathrm{Ni}$, $\mathrm{Cu}$ or another catalyst. Growth occurs through an epitaxial process starting with the adsorption of carbon on the catalyst surface, originating from hydrocarbon decomposition, either in a glow discharge or by a thermal process ${ }^{19}$.

According to the literature ${ }^{14-17,20,21} \mathrm{Ni}$ is widely used as a catalyst for nanotube and nanofiber growth. Their structure can be controlled according to the catalyst pretreatment. With the use of radio frequency plasmas, nanofibers and nanotubes ${ }^{16,18}$ were obtained in various conditions such as different precursors, gas pressures and substrate temperatures. 
Microwave plasmas have also been used to synthesize nanofibers ${ }^{22}$, nanotubes ${ }^{15}$ and nanosheets ${ }^{23}$, but with a high substrate temperature $\left(450\right.$ to $600^{\circ} \mathrm{C}$.).

It has been shown that PECVD is promising for the deposition of nanotubes, nanofibres and other carbon nanostructures, as it can be carried at lower substrate temperatures as compared to those in CVD and arc discharge processes. The elemental composition and shape of the nanoparticle catalyst deserves more research to reach carbon structures with fewer defects to facilitate their integration in Si-based devices. In this work we report an investigation on the growth of carbon nanostructures (nanotubes, nanofibers and nanosponges) from $\mathrm{C}_{2} \mathrm{H}_{2}$-Ar mixtures using a microwave PECVD system of in-house design. All nanostructures were formed onto $\mathrm{Si}$ (001) substrates coated with $\mathrm{Ni}$ or $\mathrm{Cu}$ films. Their morphology was characterized by AFM and SEM, while chemical bonding was investigated by Raman spectroscopy.

\section{Experimental}

Figure 1 is a schematic representation of the PECVD system. It consists of a reactor (quartz tube with substrate holder and microwave generator), vacuum pump of $10 \mathrm{~m}^{3} / \mathrm{h}$ pumping speed, and gas source. A Pirani gauge coupled directly to the quartz chamber was used for pressure measurements. For plasma generation, a microwave source ( $2.45 \mathrm{GHz}, 500$ Watt) was employed. Acetylene $\left(\mathrm{C}_{2} \mathrm{H}_{2}\right.$, $99,99 \%$ pure) was used as the precursor gas, mixed with argon (99,99\% purity). The substrates, $\mathrm{Si}(001), 1 \times 1 \mathrm{~cm}^{2}$, were cleaned at the RCA Cleaning Center of the Center for Semiconductor Components (CCS) of the Universidade Estadual de Campinas (Unicamp). Depositions were carried out at various $\mathrm{C}_{2} \mathrm{H}_{2}$ partial pressures in the $\mathrm{C}_{2} \mathrm{H}_{2}-\mathrm{Ar}$ mixtures, with the total pressure kept at $\sim 210$ mTorr for all depositions. The reactor base pressure was $60 \mathrm{mTorr}$. In all depositions, the applied power was kept constant, and the substrate temperature did not exceed $120{ }^{\circ} \mathrm{C}$, as measured with a type-K thermocouple.

Using a dc magnetron sputtering system, working at a base pressure of $1 \times 10^{-7}$ Torr, $\mathrm{Ni}$ and $\mathrm{Cu}$ catalytic films were deposited. Their thicknesses were measured with a quartz microbalance.

To analyze the morphology of the silicon substrate and those of the $\mathrm{Cu}$ and $\mathrm{Ni}$ films, AFM images in dynamic mode were obtained, using a Shimadzu microscope model SPM9700, of the Universidade Federal do Triângulo Mineiro - UFTM.

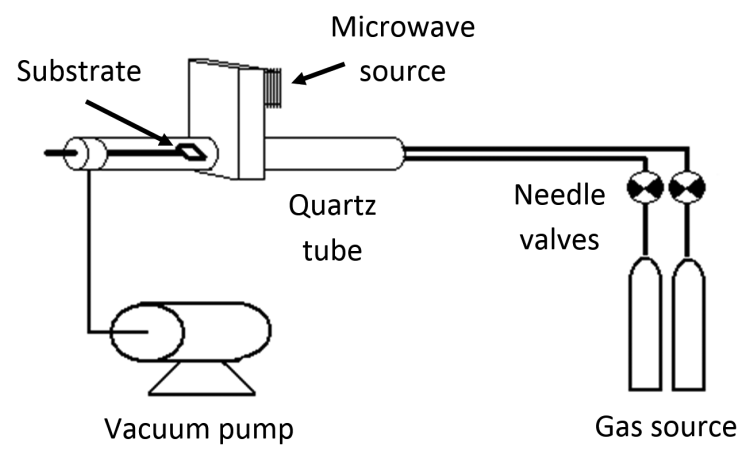

Figure 1. Schematic representation of the PECVD system.
The average roughness of the $\mathrm{Si}$ and $\mathrm{Ni}$ and $\mathrm{Cu}$ films were determined using the 9700 Scanning Probe Microscopy software provided by the Shimadzu Corporation.

The morphology of carbon nanostructures surfaces were investigated by scanning electron microscopy using the Dual Beam FIB/SEM (Focused Ion Beam/Scanning Electron Microscopy) Model Nanolab Nova 200 of CCS-Unicamp. All images were obtained in the secondary electron mode, using an electron beam of $5 \mathrm{kV}$ and $0.4 \mathrm{nA}$. We used the software UTHSCSA Image Tool ${ }^{24}$ to estimate the average diameters and height of the nanostructures and their standard deviations. A number of particles (20) was then chosen and their sizes individually measured and stored by the software.

Chemical bonding in the carbon nanostructures was investigated with a confocal Raman Spectroscope, model Ntegra Spectra from NT MDT.Co of CCS-Unicamp. The $473.8 \mathrm{~nm}$ line of a semiconductor laser was used for excitation.

\section{Results and Discussion}

Various samples ( 26), deposited at different $\mathrm{C}_{2} \mathrm{H}_{2}$ partial pressures and during the same time interval (20 minutes), on either $\mathrm{Ni}$ or $\mathrm{Cu} 3 \mathrm{~nm}$ thick catalytic films were investigated in this work. As shown in Table 1, samples are labeled by a number (the $\mathrm{C}_{2} \mathrm{H}_{2}$ partial pressure in $\mathrm{mTorr}$ ), followed by the catalyst chemical symbol. The $\mathrm{Ar}$ and $\mathrm{C}_{2} \mathrm{H}_{2}$ partial pressures used in the depositions are also given. In all depositions, the substrates did not exceed the temperature $120^{\circ} \mathrm{C}$

Figure 2 shows AFM pictures of the bare Si substrate, and of the $3 \mathrm{~nm} \mathrm{Cu}$ and Ni films. An average surface roughness of $0.178 \mathrm{~nm}$ was measured for the Si surface, typical of Si wafers (Figure 2a). For the $\mathrm{Cu}$ and the Ni films (Figures 2b, c) the average roughnesses were 0.358 and $0.227 \mathrm{~nm}$, respectively. As revealed by the pictures, the films consist of metal particles that completely cover the substrates. Figures $2 \mathrm{~b}$, c are representative of the surfaces of all catalytic films of this work as they were deposited onto a Si wafer which was subsequently cut into pieces of $1 \times 1 \mathrm{~cm}^{2}$.

Different nanostructures were obtained depending on the $\mathrm{C}_{2} \mathrm{H}_{2}$ partial pressure. The lowest one ( $\left.34 \mathrm{mTorr}\right)$ is responsible for the structures shown in Figure 3. Nearly-spherical fine particles of relatively uniform diameter $(42 \pm 5 \mathrm{~nm})$ are

Table 1. Argon and $\mathrm{C}_{2} \mathrm{H}_{2}$ partial pressures in the synthesis of each sample. Thickness of $\mathrm{Ni}$ and $\mathrm{Cu}$ catalytic films: $3 \mathrm{~nm}$. Deposition time: 20 minutes. Maximum temperature during depositions: $120^{\circ} \mathrm{C}$.

\begin{tabular}{cccc}
\hline Sample & Catalyst & $\begin{array}{c}\text { Argon } \\
\text { pressure } \\
\text { (mTorr) }\end{array}$ & $\begin{array}{c}\text { Acetylene } \\
\text { pressure } \\
\text { (mTorr) }\end{array}$ \\
\hline $34 \mathrm{Ni}$ & $\mathrm{Ni}$ & 110 & 34 \\
$34 \mathrm{Cu}$ & $\mathrm{Cu}$ & 110 & 34 \\
$64 \mathrm{Ni}$ & $\mathrm{Ni}$ & 70 & 64 \\
$64 \mathrm{Cu}$ & $\mathrm{Cu}$ & 70 & 64 \\
$70 \mathrm{Ni}$ & $\mathrm{Ni}$ & 70 & 70 \\
$70 \mathrm{Cu}$ & $\mathrm{Cu}$ & 70 & 70 \\
$79 \mathrm{Ni}$ & $\mathrm{Ni}$ & 60 & 79 \\
$79 \mathrm{Cu}$ & $\mathrm{Cu}$ & 60 & 79 \\
$100 \mathrm{Ni}$ & $\mathrm{Ni}$ & 50 & 100 \\
$100 \mathrm{Cu}$ & $\mathrm{Cu}$ & 50 & 100 \\
\hline
\end{tabular}


formed on top of the Ni film (Figure 3a). A completely different structure is exhibited by the film grown onto the $\mathrm{Cu}$ catalyst. As can be seen in Figure 3b, such structure shows nanoholes of a rather large hole size distribution (308 $\pm 56 \mathrm{~nm}$ average).

Nanoholes are also observed in films grown over both catalysts at the $\mathrm{C}_{2} \mathrm{H}_{2}$ pressure of $64 \mathrm{mTorr}$ as shown in Figure 4. Average hole diameters of $276 \pm 77$ and $217 \pm 40 \mathrm{~nm}$ were measured in samples $64 \mathrm{Ni}$ and $64 \mathrm{Cu}$, respectively.

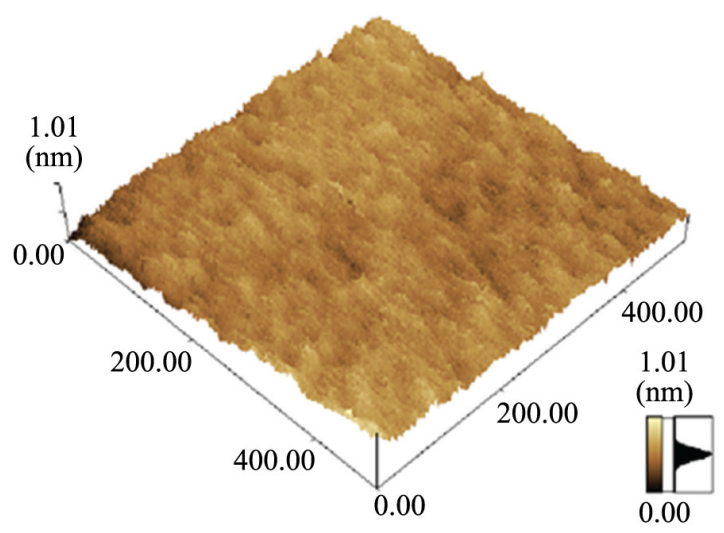

(a)

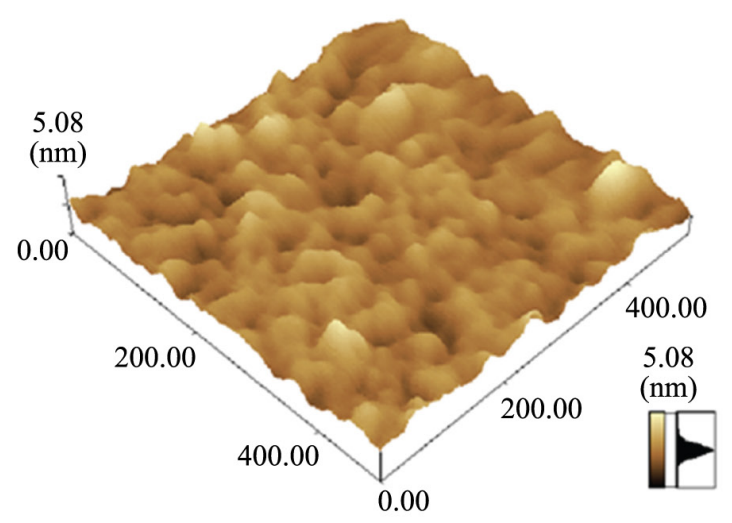

(b)

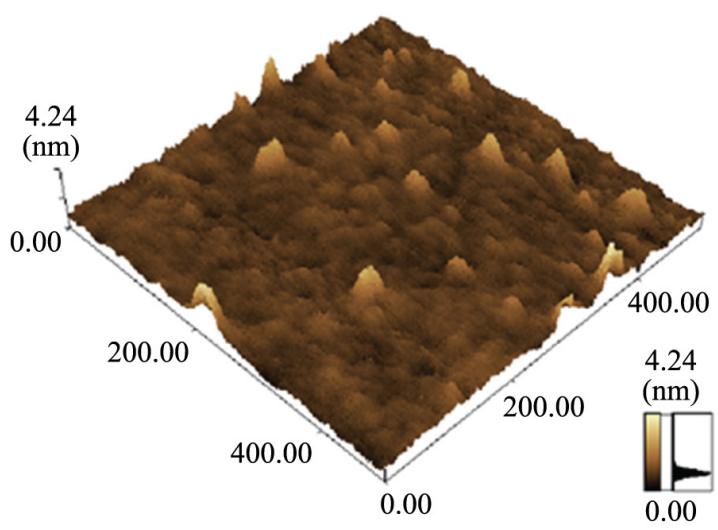

(c)

Figure 2. AFM images of the $\mathrm{Si}$ substrate (a) and $\mathrm{Ni}$ (b) and $\mathrm{Cu}$ (c) $3 \mathrm{~nm}$ catalytic films.
The early stages of formation of nanotubes with nanospheres in their tips are shown in Figure 5 for samples synthesized at $70 \mathrm{mTorr} \mathrm{C}_{2} \mathrm{H}_{2}$. The average diameters of the nanospheres are $56 \pm 12$ and $46 \pm 6 \mathrm{~nm}$ for samples $70 \mathrm{Ni}$ and $70 \mathrm{Cu}$, respectively.

The reasons for the formation of nanoholes and nanospheres, as observed in Figures 4 and 5, are not completely clear at the moment. Probably, it can be attributed to local nonuniformities of the catalyst film resulting in higher intensity of the catalytic process in some areas. In turn, this can lead to fast increase of the local temperature ("hot spots"), as the process to obtain graphitic layers during precipitation from solid solutions of carbon in metals like $\mathrm{Ni}$ or $\mathrm{Cu}$ is known to be highly exothermic $^{20}$. Finally, this local overheating of the sample can result in more intense and dense formation of carbon nanotubes near the center of the hot spot area eventually forming agglomerated structures such as nanospheres .

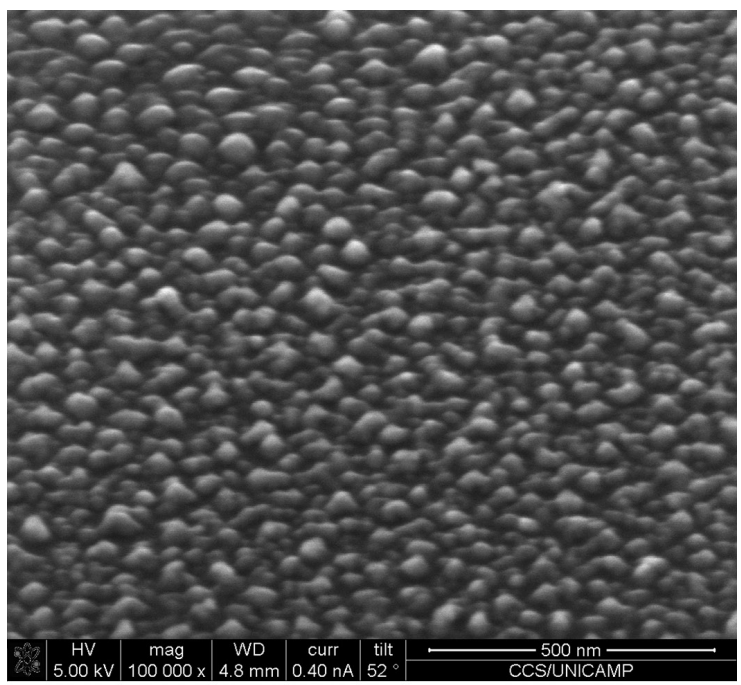

(a)

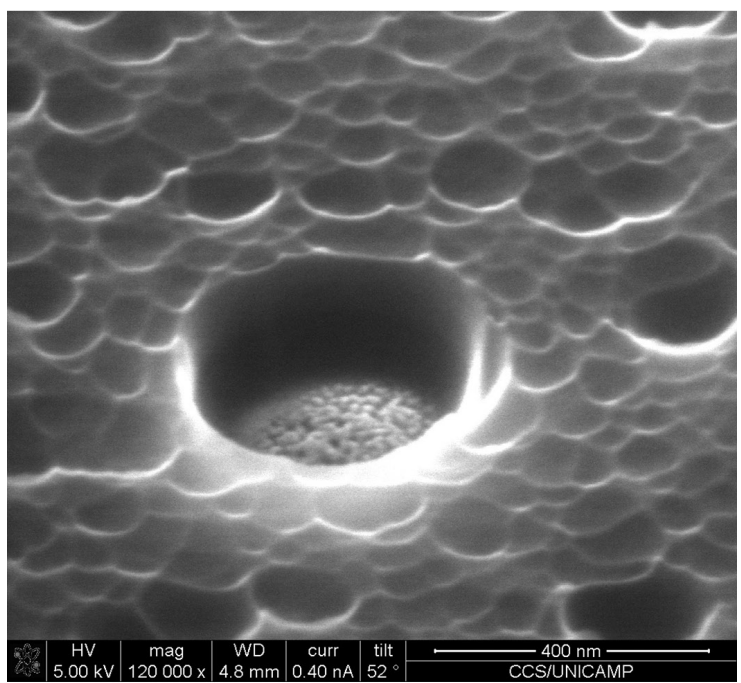

(b)

Figure 3. SEM images of structures grown at $34 \mathrm{mTorr} \mathrm{C}_{2} \mathrm{H}_{2}$ onto $3 \mathrm{~nm} \mathrm{Ni}$ (a) and $\mathrm{Cu}$ (b) catalytic films. (Samples $34 \mathrm{Ni}$ and $34 \mathrm{Cu}$ ). 


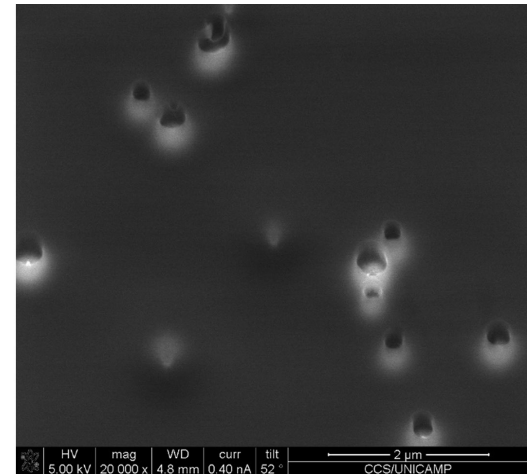

(a)

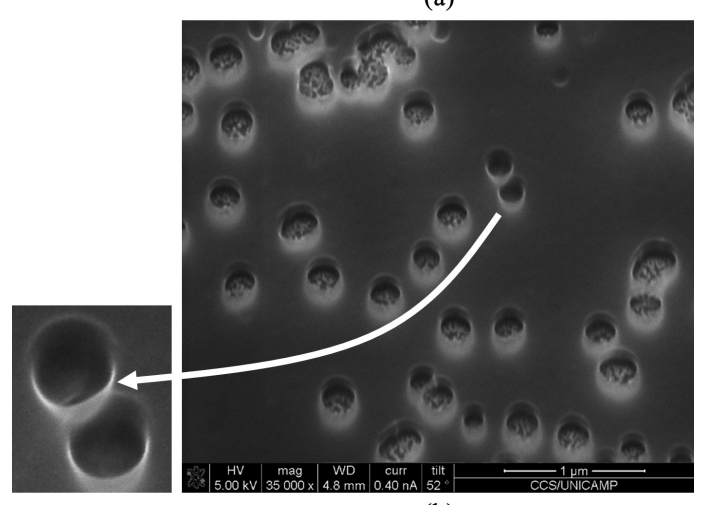

(b)

Figure 4. SEM images of structures grown at $64 \mathrm{mTorr}_{2} \mathrm{H}_{2}$ onto $3 \mathrm{~nm} \mathrm{Ni}$ (a) and $\mathrm{Cu}$ (b) catalytic films.(Samples 64Ni and 64Cu).

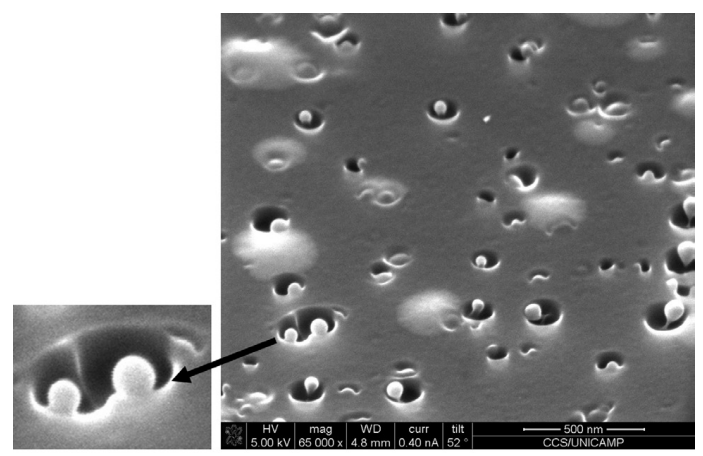

(a)

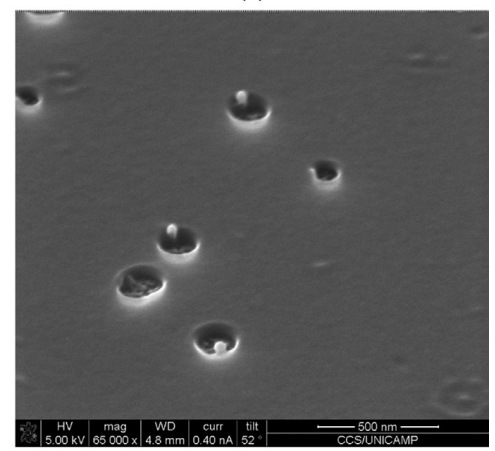

(b)

Figure 5. SEM images of structures grown at $70 \mathrm{mTorr}_{2} \mathrm{H}_{2}$ onto $3 \mathrm{~nm} \mathrm{Ni}$ (a) and $\mathrm{Cu}$ (b) catalytic films.(Samples 70Ni and 70Cu). The inset is a magnified picture of the region showing two nanotubes growing from the nanohole resulting from coalescence of two holes.
Some certain amount of carbon-carbon species present on the sample surface can contribute to the fast nanotubes growth described above. However, there is no carbon species enough coming into the catalytic particle to sustain the nanotube growth and generate long tubes. Since the process starts at the base (base-growth model discussed below) the carbon found at the nanotube top does not precipitate after its growth, remaining on the tip in a nanosphere format. As nanospheres are relatively weakly linked to the surface, they may be lost during post-processing manipulations. This can explain the lack of nanospheres in some cases.

Figure 6 shows images of films grown at 79 mTorr $\mathrm{C}_{2} \mathrm{H}_{2}$. Figures $6 \mathrm{a}, \mathrm{b}$ correspond to samples $79 \mathrm{Ni}$ and $79 \mathrm{Cu}$, respectively. The high concentration of carbon or carbon-containing species in the discharge, compared to that of the previous depositions, provided a more extensive and complete formation of carbon structures. The average heights of nanofibers were $343 \pm 32 \mathrm{~nm}$ and $381 \pm 16 \mathrm{~nm}$ for samples $100 \mathrm{Ni}$ and $100 \mathrm{Cu}$, respectively. While the average diameter calculated at half height for samples $79 \mathrm{Ni}$ and $79 \mathrm{Cu}$ were $47 \pm 14$ and $28 \pm 8 \mathrm{~nm}$, respectively.

We present herein some ideas on the dynamics of the sponge-like structures. In the early stages of their formation, only single nanotubes grow as exemplified in Figure 5. As deposition goes on, more single nanotubes are formed and their heights increase. At the same time, their associated

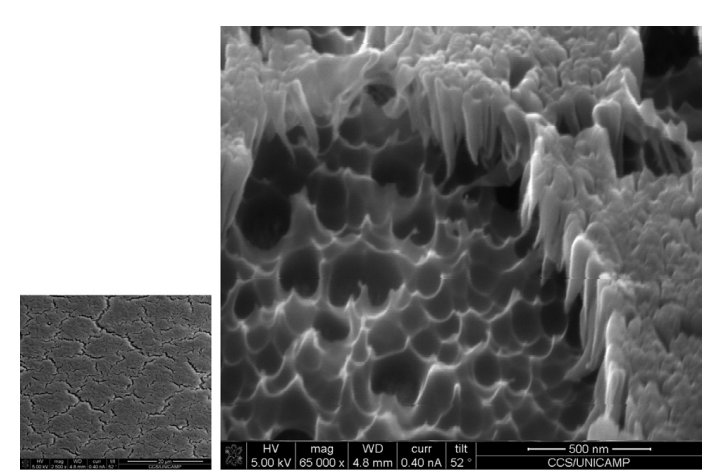

(a)

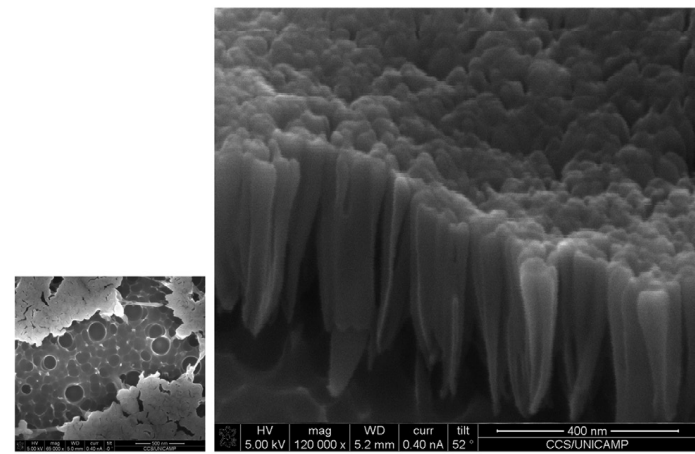

(b)

Figure 6. $\mathrm{SEM}$ images of structures grown at $79 \mathrm{mTorr}_{2} \mathrm{H}_{2}$ onto $3 \mathrm{~nm} \mathrm{Ni}$ (a) and $\mathrm{Cu}$ (b) catalytic films.(Samples 79Ni and $79 \mathrm{Cu}$ ). The upper and lower insets are from the same samples $(79 \mathrm{Ni}$ and $79 \mathrm{Cu}$, respectively) and were taken with the microscope electron beam at perpendicular incidence. The magnification of the insets differ from those of the larger images. 
holes increase in diameter and eventually coalesce, forming larger holes with two or more nanotubes, depending on the number of holes undergoing coalescence. In the inset of Figure 5a, coalescence of two nanoholes with their corresponding nanotubes can be seen. Figure 7 (to be later discussed) exemplifies coalescence of more than two holes. As the nanotubes grow, they laterally touch each other from the same hole, forming nanotube bundles. With continuation of the deposition process, hole coalescence is increased and bundle growth continues, reaching a stage in which bundles from neighbor holes touch each other forming an entangled sponge-like structure as seen in Figure 6. It is clear that this structure partially or totally blocks the arrival of precursor species to the catalytic surfaces, either extinguishing, or greatly reducing, nanotube formation.

Figure 6 shows the nanofibers, or nanotube bundles which do not uniformly cover the substrates forming a carbon sponge-like structure on surface. The bundle coverage shows cracks, as seen in the upper inset of the figure, taken from sample $79 \mathrm{Ni}$ at a magnification lower than that of Figure 6a. The regions uncovered by the bundles (Figures 6a, b and its inset) are actually portions of the cracks. We have never observed nanotubes (and their associated nanospheres) at early stages of growth in the substrate regions of the cracks. This strongly indicates that formation of cracks is a post-deposition process, occurring spontaneously or during sample handling. If cracks were formed during deposition, the observation of nanospheres would be highly probable.

It is interesting to note that despite the blocking effect of the nanotube bundles to the transit of gas-phase nanotube precursor species to the catalyst surface, nanotubes can be observed in their early stages of growth among bundles in high density regions. This is illustrated in the micrographs of Figure 7, for samples synthesized at $79 \mathrm{mTorr} \mathrm{C}_{2} \mathrm{H}_{2}$

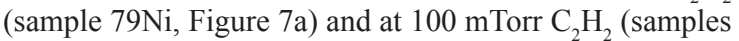
$100 \mathrm{Ni}$ and $100 \mathrm{Cu}$, Figure $7 \mathrm{~b}$, c, respectively). Comparing the images, it becomes evident that the population of the nanospheres in the samples deposited at higher $\mathrm{C}_{2} \mathrm{H}_{2}$ pressure are incomparably higher. It seems that the higher density of nanotube precursor species in the plasma at $100 \mathrm{mTorr}$ $\mathrm{C}_{2} \mathrm{H}_{2}$ pressure overruns the blocking effect of the bundles to reach the $\mathrm{Ni}$ and $\mathrm{Cu}$ surfaces.

As for the larger holes in Figures 7b, c, their diameters are about 300 and $400 \mathrm{~nm}$, respectively, and several nanotubes grow from their bottoms. According to our previous discussion on the dynamics of formation of the sponge-like structures, these holes result from coalescence of more than two holes, as in the early stage of nanotubes formation when a single hole can be seen for each nanotube. Furthermore, the structures seen in Figures 7b, c, can be considered as bundle precursors, i. e., bundles in their early stage of formation.

From the high definition of the SEM images (Figures 3-7), the so-called base growth mechanism ${ }^{16,19,25}$ is evident as no catalytic metal particles can be observed on the nanotube tips. At least two reasons point to this growth mode. The first one is the low substrate temperature that did not exceed $120{ }^{\circ} \mathrm{C}$ in any deposition, as previously noted. Owing to the low temperature, the catalyst nanoparticles do not melt, and nanofiber growth occurs by dissociation of the precursor species and subsequent carbon diffusion in the particles. The other reason is the strong adhesion of the metal particles to the Si substrate, typical of the sputtering process. In fact, Wang \& Moore ${ }^{11}$ have attributed to this high adhesion the base growth mechanism they observed in the formation of nanotubes grown on $\mathrm{Fe}$ and $\mathrm{Ni}$ catalysts sputter-deposited onto Si substrates.

Figure 8 shows the Raman spectrum for sample 79Ni. Pronounced peaks are seen readily identified as the D (disorder) and $\mathrm{G}$ (graphitic) bands at 1367 and $1587 \mathrm{~cm}^{-1}$, respectively ${ }^{26-28}$. The high intensity of the $\mathrm{G}$ band is considered as an evidence of the high sp2 carbon density in the nanofibers ${ }^{27}$ while the overlapping of the $\mathrm{G}$ and $\mathrm{D}$ bands is interpreted as a mixture of sp2 and sp3 bonding states ${ }^{28}$.

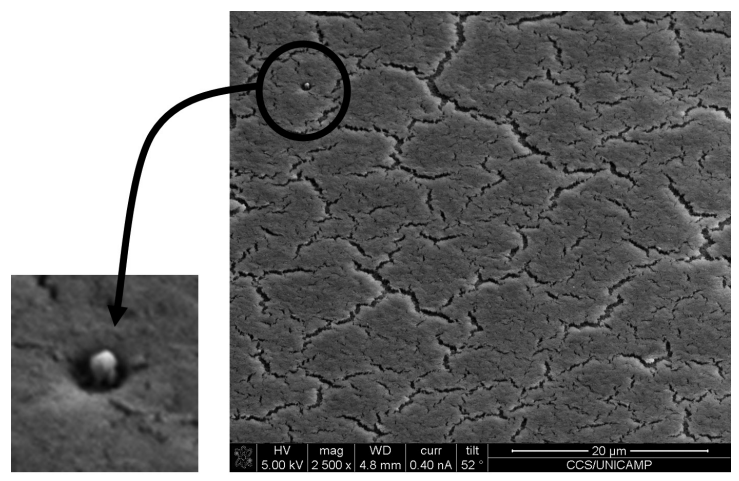

(a)

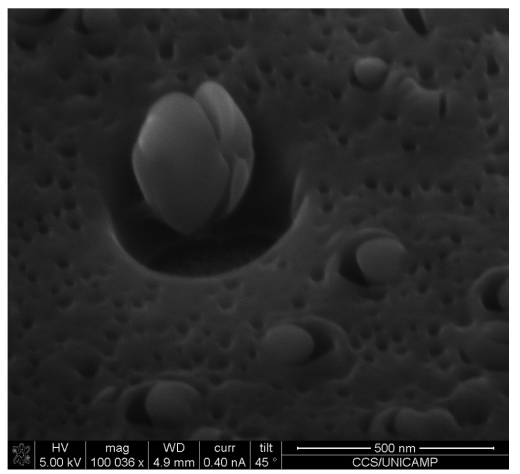

(b)

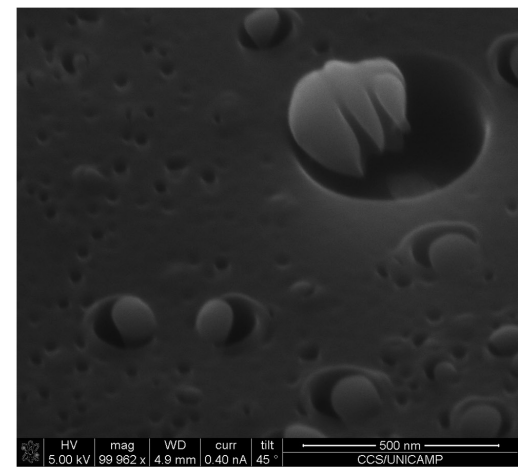

(c)

Figure 7. SEM images of structures grown at $79 \mathrm{mTorr}_{2} \mathrm{H}_{2}$ onto $3 \mathrm{~nm} \mathrm{Ni}$ catalytic film (sample $79 \mathrm{Ni}$, uppermost picture) and at $100 \mathrm{mTorr}_{2} \mathrm{H}_{2}$ onto $3 \mathrm{~nm} \mathrm{Ni}(\mathrm{b})$ and $\mathrm{Cu}$ (c) catalytic films. The inset is a magnified picture of the region showing a nanosphere. 


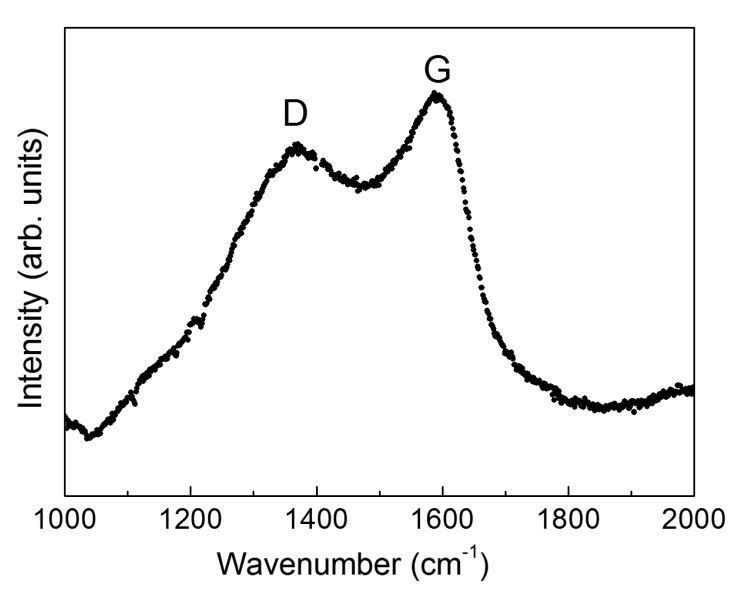

Figure 8. Raman spectrum of nanofibers deposited at 79 mTorr $\mathrm{C}_{2} \mathrm{H}_{2}$ (sample $79 \mathrm{Ni}$ ).

The carbon nanofibers shown in Figures $6 a, b$ and $7 a$ formed by defective nanotubes bundles have sp 2 carbons in its crystal lattice, evidenced by the band at $1587 \mathrm{~cm}^{-1}$ (G band) observed in Figure 8. The latter has a higher intensity than that of the shoulder formed by the $\mathrm{D}$ band at $1367 \mathrm{~cm}^{-1}$ indicating a combination of $\mathrm{sp} 3$ and $\mathrm{sp} 2$ hybridizations in the nanofiber structure. But in this case, the linewidths are larger than those in crystalline 2D graphite, observed in crystalline carbon nanotubes ${ }^{27}$ due to the presence of residual amorphous carbon.

\section{References}

1. Kroto HW, Heath JR, O'Brien SC, Curt RF and Smalley RE. C60:Buckminsterfullerene. Nature. 1985; 318(6042):162-163. http://dx.doi.org/10.1038/318162a0.

2. Iijima S. Helical microtubules of graphitic carbon. Nature. 1991; 354(6348):56-58. http://dx.doi.org/10.1038/354056a0.

3. Herbst MH, Macêdo MIF and Rocco AM. Tecnologia dos Nanotubos de carbono: tendências e perspectivas de uma área multidisciplinar. Quimica Nova. 2004; 27(6):986-992. http:// dx.doi.org/10.1590/S0100-40422004000600025.

4. Stankovich S, Dikin DA, Dommett GH, Kohlhaas KM, Zimney EJ, Stach EA, et al. Graphene-based composite materials. Nature. 2006; 442(7100):282-286. http://dx.doi.org/10.1038/ nature04969. PMid:16855586.

5. Martel R, Schmidt T, Shea HR, Hertel T and Avouris P. Single- and multiwall carbon nanotube field-effect transistors. Applied Physics Letters. 1998; 73(17):2447-2449. http://dx.doi. org/10.1063/1.122477.

6. Gelamo RV, Rouxinol FP, Verissimo C, Bica de Moraes MA and Moshkalev SA. Gas and pressure sensors based on multi-wall carbon nanotubes: study of sensing mechanisms. Sensor Letters. 2010; 8(3):488-492. http://dx.doi.org/10.1166/s1.2010.1299.

7. Gelamo RV, Rouxinol FP, Verissimo C, Vaz AR, Bica de Moraes MA and Moshkalev SA. Low-temperature gas and pressure sensor based on multi-wall carbon nanotubes decorated with Ti nanoparticles. Chemical Physics Letters. 2009; 482(4-6):302306. http://dx.doi.org/10.1016/j.cplett.2009.10.019.

8. An KH, Jeon KK, Heo JK, Lim SC, Bae DJ and Lee YH. Highcapacitance supercapacitor using a nanocomposite electrode of single-walled carbon nanotube and polypyrrole. Journal of the

\section{Conclusions}

We have shown that carbon nanotubes can be successfully synthesized using microwave-assisted PECVD. The PECVD system herein used is simple and inexpensive. Furthermore, the procedure adopted does not require any elaborated previous substrate treatment such as thermal annealing or holographic processes. The low substrate temperature $\left(120^{\circ} \mathrm{C}\right.$, at most $)$ during deposition is an advantage to avoid the inconvenient temperature effect in the substrate in which nanotubes are to be deposited.

Aside from single nanotubes, different carbon nanostructures (nanotube precursors, nanoholes, nanofibers and nanosponges) were observed depending on the $\mathrm{C}_{2} \mathrm{H}_{2}$ partial pressure on the gas mixture. The well-defined images of the carbon nanotubes and of their coalescence provide strong evidence for the base-growth mechanism proposed in other investigations.

The dynamics of carbon structures, has been discussed and we have seen that nanohole coalescence is an important step in carbon bundle formation. Furthermore, we have observed nanoholes without nanotubes. We propose that nanotubes rising from the bottom of holes existed previously existed but they can be lost during post deposition manipulation.

From the Raman spectrum, the sp2-nature of the carbon nanotubes bundles and the existence of mixed sp2-sp 3 bond states were clearly evidenced.

Electrochemical Society. 2002; 149(8):A1058-A1062. http:// dx.doi.org/10.1149/1.1491235.

9. Foldvari M and Bagonluri M. Carbon nanotubes as functional excipients for nanomedicines: II. Drug delivery and biocompatibility issues. Nanomedicine: Nanotechnology, Biology, and Medicine. 2008; 4(3):183-200. http://dx.doi.org/10.1016/j.nano.2008.04.003. PMid:18550450.

10. Grill A. Diamond-like carbon: state of the art. Diamond and Related Materials. 1999; 8(2-5):428-434. http://dx.doi. org/10.1016/S0925-9635(98)00262-3.

11. Melechko AV, Klein KL, Fowlkes JD, Hensley DK, Merkulov IA, McKnight TE, et al. Control of carbon nanostructure: From nanofiber toward nanotube and back. Journal of Applied Physics. 2007; 102(7):074314. http://dx.doi.org/10.1063/1.2786710.

12. Ren ZF, Huang ZP, Xu JW, Wang JH, Bush P, Siegal MP, et al. Synthesis of large arrays of well-aligned carbon nanotubes on glass. Science. 1998; 282(5391):1105-1107. http://dx.doi. org/10.1126/science.282.5391.1105. PMid:9804545.

13. Pham-Huu C, Vieira R, Louis B, Carvalho A, Amadou J, Dintzer $\mathrm{T}$, et al. About the octopus-like growth mechanism of carbon nanofibers over graphite supported nickel catalyst. Journal of Catalysis. 2006; 240(2):194-202. http://dx.doi.org/10.1016/j. jcat.2006.03.017.

14. Chen Y, Guo L, Johnson D and Prince R. Plasma-induced low-temperature growth of graphitic nanofibers on nickel substrates. Journal of Crystal Growth. 1998; 193(3):342-346. http://dx.doi.org/10.1016/S0022-0248(98)00538-7.

15. Choi WS, Choi S-H, Hong B and Lee J-H. Growth of carbon nanotubes on glass substrate by MPECVD. Materials Science and Engineering C. 2006; 26(5-7):1215-1218. http://dx.doi. org/10.1016/j.msec.2005.09.065. 
16. Wang $\mathrm{H}$ and Moore JJ. Low temperature growth mechanisms of vertically aligned carbon nanofibers and nanotubes by radio frequency-plasma enhanced chemical vapor deposition. Carbon. 2012; 50(3):1235-1242. http://dx.doi.org/10.1016/j. carbon.2011.10.041.

17. Hofmann S, Ducati C, Robertson J and Kleinsorge B. Lowtemperature growth of carbon nanotubes by plasma-enhanced chemical vapor deposition. Applied Physics Letters. 2003; 83(1):135-137. http://dx.doi.org/10.1063/1.1589187.

18. Löffler R, Häffner M, Visanescu G, Weigand H, Wang X, Zhang $\mathrm{D}$, et al. Optimization of plasma-enhanced chemical vapor deposition parameters for the growth of individual vertical carbon nanotubes as field emitters. Carbon. 2011; 49(13):41974203. http://dx.doi.org/10.1016/j.carbon.2011.05.055.

19. Dresselhauss MS, Dresselhauss G and Avouris P. Carbon nanotubes: synthesis, structure, properties and applications. Berlin: Springer; 2001.

20. Moshkalev SA and Verissimo C. Nucleation and growth of carbon nanotubes in catalytic chemical vapor deposition. Journal of Applied Physics. 2007; 102(4):044303. http://dx.doi. org/10.1063/1.2769354.

21. Kolahdouz Z, Kolahdouz M, Ghanbari H, Mohajerzadeh $\mathrm{S}$, Naureen $\mathrm{S}$ and Radamson $\mathrm{HH}$. Substrate engineering for $\mathrm{Ni}$-assisted growth of carbon nano-tubes. Materials Science and Engineering B. 2012; 177(17):1542-1546. http://dx.doi. org/10.1016/j.mseb.2012.01.021.
22. Hoshi F, Tsugawa K, Goto A, Ishikura T, Yamashita S, Yumura $\mathrm{M}$, et al. Field emission and structure of aligned carbon nanofibers deposited by ECR-CVD plasma method. Diamond and Related Materials. 2001; 10(2):254-259. http://dx.doi.org/10.1016/ S0925-9635(00)00476-3.

23. Wang Z, Shoji M and Ogata H. Carbon nanosheets by microwave plasma enhanced chemical vapor deposition in CH4-Ar system. Applied Surface Science. 2011; 257(21):9082-9085. http:// dx.doi.org/10.1016/j.apsusc.2011.05.104.

24. Wilcox CD, Dove SB, McDavid WD, Greer DB. UTHSCSA Image Tool. Texas: UTHSCSA; 2002.

25. Baker RTK, Barber MA, Harris PS, Feates FS and Waite RJ. Nucleation and growth of carbon deposits from the nickel catalyzed decomposition of acetylene. Journal of Catalysis. 1972; 62(1):51-62. http://dx.doi.org/10.1016/0021-9517(72)90032-2.

26. Tuinstra F. Raman spectrum of graphite. The Journal of Chemical Physics. 1970; 53(3):1126. http://dx.doi.org/10.1063/1.1674108.

27. Dresselhaus MS, Dresselhaus G, Saito R and Jorio A. Raman spectroscopy of carbon nanotubes. Physics Reports. 2005; 409(2):47-99. http://dx.doi.org/10.1016/j.physrep.2004.10.006.

28. Ferrari A and Robertson J. Interpretation of Raman spectra of disordered and amorphous carbon. Physical Review B: Condensed Matter and Materials Physics. 2000; 61(20):14095-14107. http://dx.doi.org/10.1103/PhysRevB.61.14095. 